\title{
A Framework for Automatic Exam Generation based on k-means and Genetic Algorithm
}

\author{
Sherif Samir M. Sultan \\ Department of Information Systems \\ Helwan University, Egypt
}

\author{
Manal A. Abdel-Fattah \\ Professor of Information Systems \\ Helwan University, Egypt
}

\author{
Nashat Nabil Al-Wakeel \\ Professor of Economics \\ Helwan University, Egypt
}

\begin{abstract}
Manual generate of test papers is a difficult assignment for instructors, particularly inside a brief timeframe outline. It requires a large amount of work and time to accomplish a standard nature of the test papers. question paper necessarily to consider several items such as difficulty level marks, numericalas well as theoretical contents of the paper, weightage ofquestions, and repetition of exam questions in terms of their characteristics is one of the most important problems in generating the test. The scientific contribution of this research is a proposed framework based on combine between genetic algorithms and unsupervised learning methods (k-means) to generate a test paper according to Bloom's criteria, where the k-means method collects each group of questions with the samefeatures in one group. where address the problem of the repetition of questions that have the same characteristics. In theexam paper, based on the previous step, it will be easy for the genetic algorithm to choose the best exam according to the six levels bloom's. The framework consists of several phases in the first phase, generate the questions bank in the second phase, the questions were divided into six groups that were similar intheir properties using the $\mathrm{k}$ means method, in the third phase, used a random sorting function to randomly arrange each group to ensure that the questions were not repeated when the initial population was created. Used A question bank of 800 questions including all types of questions.
\end{abstract}

\section{General Terms}

Genetic Algorithm, k-means

\section{Keywords}

Automated Exam Questions Generator, Bloom's Taxonomy, Genetic Algorithm, k-means

\section{INTRODUCTION}

The exam is a method of evaluating the instructors that is systematic and ongoing. Prepare for their students with the goal of evaluating their performance on the basis of the learning outcome. [1]. High-quality test questions can determine a student's level of achievement and can also indicate the level of effort put in by teachers and educational institutions. [2][3]. As a result, creating useful exam questions is a critical duty. Essays, short responses, true and false questions, multiple choice questions, and other types of questions can all be found on a normal examination question paper.

Exam question generation is difficult, time-consuming, and timeconsuming for instructors. [1]. question paper necessarily to consider several items such as difficulty level marks, numerical as well as theoretical contents of the paper, and weightage of questions according to the marks to cover the several capabilities of students. In addition, the following issues [4] must be addressed. [4].

- Does the question paper take into account both time and grade limits, as well as the level of difficulty?
- Is the material of the question paper appropriate in terms of subject coverage?

- Can questions be used to measure student ability at multiple levels of Taxonomy?

Manual exam paper preparation necessitates a significant amount of effort to ensure that educators adhere to all educational organization standards while preparing exam papers. It is tedious and thorough, with the possibility of human error [2].

Time constraints to generate good quality exam questions based on the institution's requirements, question style that is generated repeatedly over time, examination questions that are biased towards a certain level of difficulty, and exam questions that do not consider all six levels of Bloom's Taxonomy's cognitive domain [5].

The evolution of approaches helps instructors save time and effort when writing test questions. Genetic algorithms (GAs) are search and optimization algorithms that are based on evolutionary concepts. Also, GAs are one of the well-known machine learning algorithms. Conceptually, they mimic process of natural selection. GAsuse a parallel search to randomly select individuals from a population of candidates, apply crossover and mutate the candidates until the system meets some user- defined criterion [7]. This genetic algorithm can automatically combine test papers according to the standard of difficulty degree, knowledge level, and the proportion of questions [8]. As a result, the generator can automatically prepare new exam questions based on the Genetic Algorithm (GA).

This study aims to propose a framework for an Automated Exam Question Set Generator (AEQSG) based on theintegration the $\mathrm{k}$ means clustering with Genetic Algorithm (GA) to resolve this problem.

There are five sections to this study. Section two, the prior study, follows the introduction. The research technique is detailed in Section three, which breaks down the phases of the proposed strategy. The recommendations and results are discussed in Section four andfinally, the conclusions and future works.

\section{LITERATURE REVIEWS}

Abd Rahim, and et al, 2020. This research produced an Automated Exam Question Set Generator (AEQSG) using Utility Based Agent (UBA) and Learning Agent (LA). Moreover, AEQSG stratifies Bloom Taxonomy (BT) scaling to automate Bloom's Taxonomy (BT) difficulty level distribution and Genetic Algorithm (GA) to optimize the generation of exam question set and generate high-quality exam question set that follow educational organization's Standards. The aim of a utilitybased agent in AEQSG is to present the users an option to selection actions depended on a user's utility for each generation state. At the same time, the purpose of the learning agent in AEQSG is to learn from its previous exam results [8]. 
Paul, Dimple Valayil, 2020. The study focuses on the creation of question paper templates and their application in the dynamic generation of examination question papers. This study examines the initial population generation, chromosome encoding, genetic manipulations, and empirically verifies that the created question paper templates are best suited for the dynamic examination paper generation system employing the Genetic Algorithm (GA) and educational taxonomies. In terms of topic coverage, learning domains, and mark distribution, this new strategy outperforms previous techniques that produce assessment exams at random. The study was carried out for the Goa University Examination System. Software Engineering (SE) and Information Technology (IT) are two disciplines taught in the third year of Goa University's three-year computer science bachelor's degree program. The results of the study are a template for a matrix of shape 3 by 3 is well getting generated with a fitness value of 0.9456 which is the optimum solution [9].

Bangera Shanika, et al ,2019. The goal of this project is to make it easier for educators to give an exam question paper using a Genetic algorithm (GA). The generator can auto-generate new exam questions using GA and covers six levels of Bloom's Taxonomy to provide high-quality exam questions that can assess learners at different levels based on Bloom's cognitive scope and chapter selection. In this track, the absolute number of test questions is shown as five. The degree program normally comprises five Multiple Choice investigations. Before test questions can be created, the Automated Exam Question Generator expects teachers to choose a course code, an exam question set, and sections. The fitness value for this model has been defined as the type of test questions weightage rate based on the dimension of the psychological area secured. Because of the low fitness value, high-quality test addresses will be provided. Each experiment used a different number of parts. The weightage rate of exam questions developed using this methodology was estimated to be $70 \%$. The greatest weightage rate for exam questions is 90 percent, while the lowest weightage rate is 40 percent. The reduced number of existing questions for each Bloom's Taxonomy level in the question bank influenced the project's final outcome. [10].

Ashraf Amria, and et al, 2018. This research offered a system based on Bloom's taxonomy that allows instructors to link questions to intended learning goals. It also covers the fundamentals and requirements for creating examinations automatically. It also describes a prototype implementation of an authoring tool for creating tests to assess whether or not intended learning outcomes have been met [11].

Song, Wanli, 2018. The researchers in this paper studied online exam paper composition algorithms depends on a genetic algorithm. Then this technique is used to prepare the structure of the exam paper automatically, composites the examination content. The results of the paper online testing system based on this algorithm show that the GA is effective. On the premise of guaranteeing the quality of the test paper, ALSO improves the efficiency of online testing. The difficulty coefficient has a 30 percent difference, which influences the fairness of the students' evaluation. Furthermore, according to the user-defined circumstances, GA can acquire more than $90 \%$ of the exam papers' fitness. [7].

\section{Abd Rahim, Tengku Nurulhuda Tengku, et al, 2017.}

This study proposes an automated test question generator to address the issue of creating multiple-choice exam questions. The teacher can auto-generate new exam questions based on the Genetic Algorithm (GA) and six levels of Bloom's Taxonomy to develop high-quality exam questions that can test the various levels of learners based on Bloom's cognitive domains and educator-selected chapters. The prototype, which included 500 sample questions, was run 50 times with different amounts of chapters for each test case. It achieves a score of 90 percent for the greatest exam question weightage, with a score of 70 percent for the average exam question weightage percentage generated. The lowest weighted percentage of exam questions generated is $40 \%$. The result is influenced by the lesser number of questions in the questions bank for each Bloom's taxonomy level. [12].

Havan, Aishwarya, et al, 2016. They came up with a solution in the shape of an Automated Question Paper Generator System that employs Fuzzy and Apriority approaches. It is designed to allow universities to quickly generate question papers with random but even questions that cover most chapters of a topic at various levels and mail them to colleges. [13].

The researchers Ashok Immanuel and et al, 2015. They have proposed "Framework for Automatic Examination Paper Generation System," depended on an evaluation system where a university produces an exam every year.

The framework is dependent on the client- server architecture, it would be a three-tier model including the question gathering which would be the question bank, Question Paper Generation Algorithm which would extend logical tier, bank interface and interface for the user. This framework provides a platform to aggregate questions; classify questions, and associate questions with the syllabus of the course. This supports the build of a system that would simplify the standardization of assessment to a greater extent. It also attempts to provide flexibility in defining the classification criteria which could be distinct for every educational institution [14].

Table 1. Comparison between literature reviews

\begin{tabular}{|c|c|c|}
\hline Researchers & Objectives & Techniques \\
\hline Abd Rahim , 2020 & $\begin{array}{l}\text { Produced an automatec } \\
\text { examquestion set of } \\
\text { generator. }\end{array}$ & $\begin{array}{l}\text { Using utility based } \\
\text { agent \& Learning } \\
\text { GA to optimize the } \\
\text { generation of exam. }\end{array}$ \\
\hline $\begin{array}{l}\text { Paul, Dimple } \\
\text { Valayil,2020 }\end{array}$ & $\begin{array}{l}\text { Focus on the question } \\
\text { paper template } \\
\text { generation. }\end{array}$ & $\begin{array}{l}\text { GA } \\
\text { Educational } \\
\text { taxonomies. }\end{array}$ \\
\hline $\begin{array}{l}\text { Bangera Shanika, et } \\
\text { al ,2019 }\end{array}$ & $\begin{array}{l}\text { Generation paper on } \\
\text { GA. }\end{array}$ & $\begin{array}{l}\text { GA } \\
\text { Blooms cognitive } \\
\text { scope. }\end{array}$ \\
\hline $\begin{array}{l}\text { Ashraf Amria, and } \\
\text { et al , } 2018\end{array}$ & $\begin{array}{l}\text { Educators can use this } \\
\text { framework to map } \\
\text { questions to methods. } \\
\text { Bloom's cognitive } \\
\text { theory is the base of } \\
\text { the learning results. }\end{array}$ & $\begin{array}{l}\text { Learning } \\
\text { management system } \\
\text { Naïve Bayes, } \\
\text { support Vector, K- } \\
\text { nearest neighbor. }\end{array}$ \\
\hline Song, Wanli ,2018 & Online test paper. & GA. \\
\hline $\begin{array}{l}\text { Abd Rahim, } \\
\text { Tengku Nurrlhude } \\
\text { Tengku, et al , } \\
2017\end{array}$ & $\begin{array}{l}\text { Present an automated } \\
\text { exam question } \\
\text { generation of multiple } \\
\text { choice exam questions }\end{array}$ & $\begin{array}{l}\text { GA } \\
\text { Educational } \\
\text { taxonomies. }\end{array}$ \\
\hline
\end{tabular}




\begin{tabular}{|l|l|l|}
\hline $\begin{array}{l}\text { Havan, Aishwarya, } \\
\text { et al,2016 }\end{array}$ & $\begin{array}{l}\text { Present the answer in } \\
\text { the form of a system } \\
\text { that generates } \\
\text { automated question } \\
\text { papers. }\end{array}$ & Fuzzy algorithm. \\
\hline $\begin{array}{l}\text { Ashok Immanuel } \\
\text { and et al, 2015 }\end{array}$ & $\begin{array}{l}\text { Proposed framework } \\
\text { for automatic } \\
\text { examination paper } \\
\text { generation system } \\
\text { depended on an } \\
\text { evaluation system. }\end{array}$ & $\begin{array}{l}\text { Pattern composer } \\
\text { Syllabus engine. }\end{array}$ \\
\hline
\end{tabular}

Most of the previous studies used Genetic Algorithms to generate the exam paper, and the most difficult challenge was to generate an exam paper without repeating the questions taking into account the six levels of Blooms. The scientific contribution of the research is to introduce an improved framework based on Bloom's levels by combining genetic algorithms with unsupervised learning methods, where the unsupervised learning methods can collect each group of questions that have the same characteristics (time, degree of difficulty, class...etc.) in one group. This reduces the presence of questions that have the same characteristics and not to be repeated in the exam paper. It facilitates the work of the genetic algorithm in choosing the best exam based on levels of Blooms. also increases the accuracy of the genetic algorithm. Thus, will get a high-quality exam paper covering the six levels of knowledge.

\section{THE PROPOSED FRAMEWORK}

In this section, present the proposed framework in detail. divided the proposed framework into four sequential stages, the first stage is the question bank, the second stage is the application of the algorithm of assembly, then in the third stage, the application of the Genetic algorithm, and in the finalstage the examination paper. As shown in Figure 1.

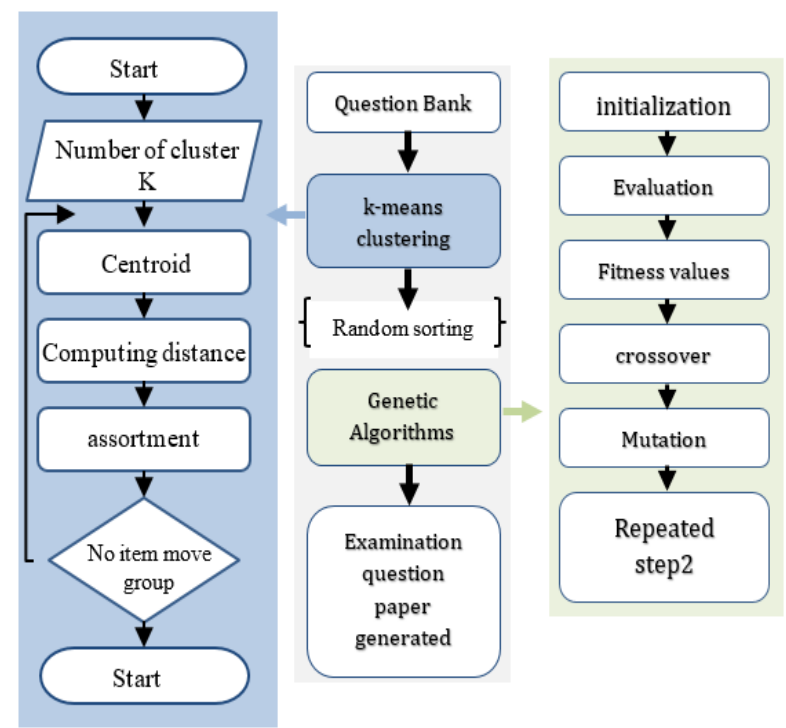

Figure 1. The Proposed Framework

\subsection{Question bank}

Previous exam questions will be processed and saved in the questions bank as input for the Automated Exam Questions Generator during this phase. In addition, the educator can develop new exam questions and save them in a question bank for later use. The Automated Exam Questions Generator creates new exam questions based on Bloom's Taxonomy's six levels.

The data set was obtained from EGI. Department of Information Systems. Course title in the database, the dataset consists of 800 rows for four consecutive years, and 9 features. As shown in Table 2 .

Table 2. Description of dataset

\begin{tabular}{|l|l|}
\hline \multicolumn{1}{|c|}{ factor } & \multicolumn{1}{c|}{ Description } \\
Question id & $\begin{array}{l}\text { ID is a unique number for every question } \\
\text { that is not repeated Such that } \\
\text { (2L_2020_1_30\%) (level_year_serial_quality) }\end{array}$ \\
\hline $\begin{array}{l}\text { course } \\
\text { code }\end{array}$ & $\begin{array}{l}\text { A Course Code is a 5-digit letters and numbers } \\
\text { code that is produced and assigned to the } \\
\text { courses generated by institutions. }\end{array}$ \\
\hline Mark & Refer to score every question \\
\hline Chapter & Refer to number of chapters \\
\hline $\begin{array}{l}\text { Question } \\
\text { type }\end{array}$ & $\begin{array}{l}\text { Refer to the question's type. Multiple choice, } \\
\text { true or false, short answer, and essay are } \\
\text { examples of question types. }\end{array}$ \\
\hline Course title & $\begin{array}{l}\text { Refer to name of course such as (database, } \\
\text { programming ... etc.) }\end{array}$ \\
\hline CLO & $\begin{array}{l}\text { Refer to course learning outcomes } \\
\text { The Bloom taxonomy cognitive level is used to } \\
\text { determine the difficulty level. In the OBE } \\
\text { documents for each course, there is a } \\
\text { predefined cognitive level. }\end{array}$ \\
\hline $\begin{array}{l}\text { Difficult } \\
\text { level }\end{array}$ & $\begin{array}{l}\text { Reflect the total time required to complete the } \\
\text { question }\end{array}$ \\
\hline Time &
\end{tabular}

\subsection{K-means algorithm}

The K-means clustering method is a partition clustering algorithm that optimizes a criterion function to group a set of objects into k clusters. [15].

At this stage, used the $\mathrm{k}$ mean technique to divide the question bank into groups that have similar properties in terms of the type of question, the time, the degree of difficulty of the question, the separation ... etc., so that get similar groups in these features to facilitate the generation of an exam paper after that through the genetic algorithm.

There are three basic steps to the technique:

(1) Choosing k objects as cluster centroids: In this phase, chose six centroids $(\mathrm{k}=6)$ based on SSE, as shown in figure 3. (2) Objects are assigned to the closest cluster based on means, and (3) centroids are updated based on the assigned data. Steps 2 and 3 are repeated until no item joins a cluster or the criteria function improves after a certain number of iterations [16]. The goal of the traditional $\mathrm{K}$-means clustering technique is to find a set $C$ of $K$ clusters $C J$ with cluster mean $c j$ in order to reduce the number of squared errors [16]. Equation 1 demonstrates this.

$$
E=\sum_{j}^{k}=1 \sum x i \in c j\|c j-x i\|^{2}
$$

$\|\ldots\|$ is the distance metric between a cluster mean and a data point $x i C$ F; $\mathrm{E}$ is the addition of square error (SSE) of objects with cluster means for $\mathrm{K}$ cluster; $\|\ldots\|$ is the distance metric between a cluster mean and a data point $x i \mathrm{Cj}$. Equation 2 demonstrates this.

$$
\|x-y\|=\sqrt{\sum_{i=1}^{v}|x i-y i|^{2}}
$$




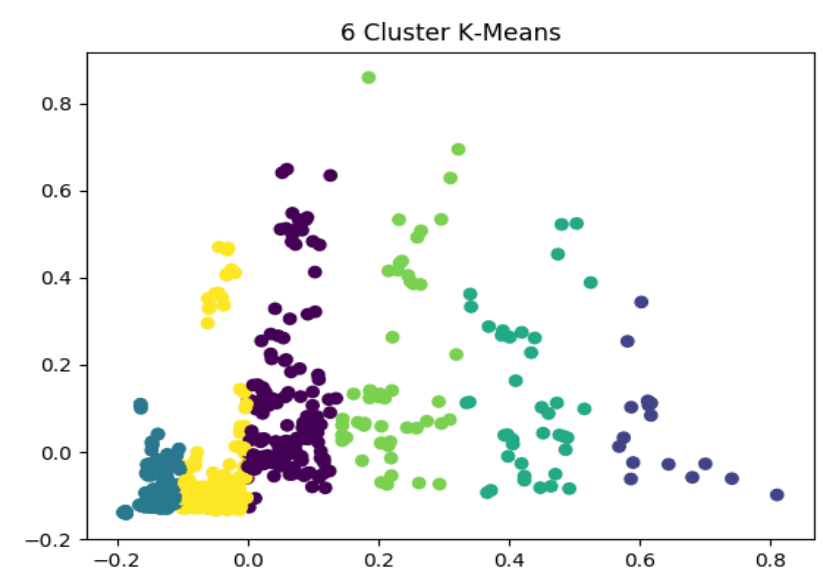

Figure 2. Example of visualization segmentation of questions bank

The following is a vector of cluster mean $C \mathrm{i}$. As show in Equation 3

$$
c j=\frac{1}{|c j|} \sum_{i \in c j} x i
$$

A flowchart of K-means clustering has been depicted, which includes six key stages. To begin, let's look at the preliminary value of centroids: Let $(\mathrm{C} 1, \mathrm{C} 2 \ldots)$ be the centroids that harmonize. Second, the object-centroid distance is calculated, which is the distance between the cluster centroid and all objects. After that, the distance matrix at iteration 0 is constructed using the Euclidean distance. Every item is represented by a column in the distance matrix. The distance of every object in the first row corresponds to the distance of every object in the second row, and the distance of every object in the second centroid corresponds to the distance of every object in the second centroid. Object clustering in the third row: Assign each object to the location with the shortest distance. Determining the centroids at iteration 1 of the 4th row: by identifying the components of all groups, the new centroid of every set is computed on the basis of these new memberships. Repeat step 2 for the fifth row. The last iteration grouping is compared in the sixth row, and this iteration states that groups are not shifted by objects. As a result, K-means clustering algorithm has become stable, and iteration is no longer required. [17].

$$
S S E=\sum_{i=1}^{n}\left(X_{I}-\bar{X}\right)^{2}
$$

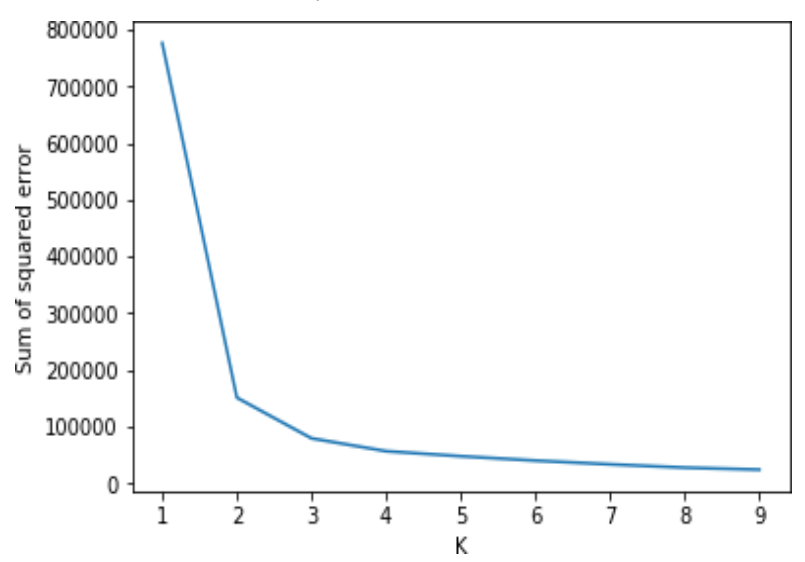

Figure 3. Results of Evaluation k-means cluster using SSE

\subsection{Random sorting}

The output of the previous assembly stage is that got 6 sets of clusters. Each cluster has a set of similar questions in its own features, at this stage, use the random sorting function to randomly arrange each cluster to ensure that it is not repeated when choosing a set of random solutions.

\subsection{Genetic algorithm}

Initialization, Evaluation, Selection, Crossover, Mutation, and Repeat are the generic processes of Genetic Algorithm [19] [20].

1) Initialization: Three initial populations will be established by picking questions at random from the questions bank. It was then separated into a number of clusters. To avoid predicting question patterns, a simple query was run beforehand to filter all of the questions in the bank, resulting in the development of new exam questions containing only questions from selected chapters and

\begin{tabular}{|c|c|c|c|c|c|c|}
\hline level & $2 \mathrm{~L}$ & $5 \mathrm{~L}$ & $5 \mathrm{~L}$ & $6 \mathrm{~L}$ & $2 \mathrm{~L}$ & $4 \mathrm{~L}$ \\
\hline Chromosome 1 & 40 & 90 & 90 & 100 & 30 & 80 \\
\hline level & $2 \mathrm{~L}$ & $4 \mathrm{~L}$ & $2 \mathrm{~L}$ & $4 \mathrm{~L}$ & $5 \mathrm{~L}$ & $2 \mathrm{~L}$ \\
\hline Chromosome 2 & 40 & 60 & 30 & 80 & 90 & 30 \\
\hline level & $2 \mathrm{~L}$ & $6 \mathrm{~L}$ & $2 \mathrm{~L}$ & $1 \mathrm{~L}$ & $4 \mathrm{~L}$ & $5 \mathrm{~L}$ \\
\hline Chromosome 3 & 40 & 100 & 30 & 20 & 80 & 90 \\
\hline level & $2 \mathrm{~L}$ & $6 \mathrm{~L}$ & $2 \mathrm{~L}$ & $1 \mathrm{~L}$ & $4 \mathrm{~L}$ & $5 \mathrm{~L}$ \\
\hline Chromosome 4 & 50 & 100 & 70 & 80 & 80 & 80 \\
\hline level & $2 \mathrm{~L}$ & $2 \mathrm{~L}$ & $3 \mathrm{~L}$ & $6 \mathrm{~L}$ & $6 \mathrm{~L}$ & $5 \mathrm{~L}$ \\
\hline Chromosome 5 & 40 & 40 & 70 & 100 & 100 & 90 \\
\hline level & $2 \mathrm{~L}$ & $3 \mathrm{~L}$ & $6 \mathrm{~L}$ & $2 \mathrm{~L}$ & $5 \mathrm{~L}$ & $5 \mathrm{~L}$ \\
\hline Chromosome 6 & 20 & 70 & 100 & 30 & 90 & 90 \\
\hline
\end{tabular}
excluding previous questions from two consecutive years.

Each population is made up of chromosomes, and each chromosome is made up of genes. Each gene represents a question in the test set, and each chromosome represents the entire set [21].

2) Evaluation (fitness values): Just when new population is generated or population is initialized, evaluation of the fitness values of the candidate solutions are carried out. Each chromosome in the population will be examined, and a fitness value for each chromosome will be calculated. The fitness value will be derived using Bloom's Taxonomy (the six levels of cognitive domains with varying degrees of ability) and the weightage percentage of quality exam questions as given in Table 3 below [2][3].

Table 3 shows the weighted average of exam question quality

\begin{tabular}{|c|c|c|}
\hline L6 & Hard & Evaluation \\
\hline L5 & Hard & Synthesis \\
\hline L4 & Medium & Analysis \\
\hline L2 & Medium & Application \\
\hline L1 & Easy & Comprehension \\
\hline & Easy & Knowledge \\
\hline
\end{tabular}

Figure 5. The Six Level BLOOM'S

The weighted average of exam question quality is determined in table 3 below based on the Bloom's taxonomy classification coverage, where Knowledge and Comprehension levels are grouped as Easy; Application and Analysis levels are grouped as the good quality of exam questions covers all three Bloom's taxonomy classifications, i.e. Easy, Medium, and Hard. 
Exam questions of medium grade contain at least two Bloom's taxonomy classifications: Easy and Medium combined, Medium and Hard combined, or Easy and Hard combined. Only one of Bloom's taxonomy classifications is covered by the poor quality of exam questions [2].

$$
\text { Fitness value }=1 / Q
$$

$$
Q=\begin{gathered}
\sum \text { weightage } \\
\text { number of genes }
\end{gathered}
$$

Table 3. Fitness value for each chromosome

\begin{tabular}{|c|c|}
\hline Chromosome & Fitness values \\
\hline 1 & 0.014 \\
\hline 2 & 0.018 \\
\hline 3 & 0.016 \\
\hline
\end{tabular}

\begin{tabular}{|c|c|}
\hline Chromosome & Fitness values \\
\hline 4 & 0.013 \\
\hline 5 & 0.013 \\
\hline 6 & 0.015 \\
\hline
\end{tabular}

5) Selection: more copies solutions are allocated by means of selection with high-level fitness and the idea of survival possibilities of being fittest is imposed on the solutions of the candidates. The main notion choice is to choose the solutions which are better and favoring them over other ones. Therefore, many procedures of selection were suggested to accomplish this notion. Based on the fitness value or quality of questions.

Table 4. Quality of Exam Questions Weightage Percentage

\begin{tabular}{|c|c|c|l|}
\hline \multirow{7}{*}{ 6Level } & $100 \%$ & $\begin{array}{l}\text { e.g. Knowledge, } \\
\text { Comprehension, Application, } \\
\text { Analysis, Synthesis and } \\
\text { Evaluation }\end{array}$ \\
\cline { 2 - 4 } & 5Level & $90 \%$ & $\begin{array}{l}\text { e.g. Knowledge, } \\
\text { Comprehension, Application, } \\
\text { Analysis and Evaluation }\end{array}$ \\
\cline { 2 - 4 } & 4Level & $80 \%$ & $\begin{array}{l}\text { e.g. Knowledge, } \\
\text { Comprehension, Analysis and } \\
\text { Synthesis }\end{array}$ \\
\cline { 2 - 4 } & 3Level & $70 \%$ & $\begin{array}{l}\text { e.g. Comprehension, Analysis } \\
\text { and Synthesis }\end{array}$ \\
\hline \multirow{5}{*}{ Medium } & 4Level & $60 \%$ & $\begin{array}{l}\text { e.g. Comprehension, } \\
\text { Application, Analysis and } \\
\text { Evaluation }\end{array}$ \\
\cline { 2 - 4 } & 3Level & $50 \%$ & $\begin{array}{l}\text { e.g. Knowledge, Application } \\
\text { and Evaluation }\end{array}$ \\
\cline { 2 - 4 } 2Level & $40 \%$ & e.g. Analysis and Synthesis \\
\hline \multirow{2}{*}{ Bad } & 2Level & $30 \%$ & e.g. Application and Analysis \\
\cline { 2 - 4 } & 1Level & $20 \%$ & e.g. Synthesis \\
\hline
\end{tabular}

The best population is determined by the fitness function with the lowest value among the six original populations, and it is chosen using the Roulette Wheel [22] [23].

\begin{tabular}{|l|l|l|l|l|l|l|}
\hline Parent 1 & 40 & 90 & 90 & 100 & 30 & 80 \\
\hline Parent 2 & 40 & 90 & 90 & 100 & 30 & 80 \\
\hline
\end{tabular}

Figure 6. Show the parent based on lowest values of fitness function

3) Crossover: Combining parts of two or more of the main solutions to have new and better solutions (i.e. offspring) [21]. There are several ways to achieve this and the efficient performance relies on the recombination mechanism which should be properly designed.
To improve the fitness value of the created chromosome, a single crossover approach is used, with the crossover point chosen at random. Figure 6 illustrates the situation.

\begin{tabular}{|l|c|c|c|c|c|c|}
\hline Parent 1 & 40 & 90 & 90 & 80 & 80 & 80 \\
\hline Parent 2 & 50 & 100 & 70 & 100 & 100 & 90 \\
\hline Parent 3 & 40 & 40 & 70 & 100 & 30 & 80 \\
\hline
\end{tabular}

Figure 7. Show mating pool for the parents

4) Mutation: Depending on the mutation rate, a mutation process will replace a few genes with new genes. In other words, questions that appear on the exam more than once will be removed and replaced with new questions based on the mutation rate.

Finally, the procedure will be repeated from step 2 (assessment) through step 5 (mutation) until the best solution or complete loop is discovered. By comparing all fitness values, the lowest fitness value can be found. To assess optimal fitness, the coverage of Bloom's Taxonomy levels in created exam questions is used.

\section{EXAMINATION QUESTION PAPER}

According to the results of the trial, the weighted average of exam questions is $84 \%$. The highest weighted exam question percentage is $95 \%$, while the lowest is $60 \%$. Since there are fewer questions for each Bloom's Taxonomy stage in the issue bank, the final outcome of this study is influenced.

Table 5. Comparison between results of literature review

\begin{tabular}{|l|l|l|}
\hline \multicolumn{1}{|c|}{ Studies } & \multicolumn{1}{c|}{$\begin{array}{c}\text { Highest } \\
\text { Weightage Rate }\end{array}$} & \multicolumn{1}{c|}{$\begin{array}{c}\text { Least Weightage } \\
\text { Rate }\end{array}$} \\
\hline $\begin{array}{l}\text { Bangera } \\
\text { Ashanika } \\
\text { Shanthi,2019 }\end{array}$ & $\begin{array}{l}\text { The weightage rate } \\
\text { of exam questions } \\
\text { is normally } \\
\text { estimated to be } \\
70 \% .\end{array}$ & $\begin{array}{l}\text { The lowest } \\
\text { percentage of } \\
\text { exam questions } \\
\text { that are weighted is } \\
40 \% .\end{array}$ \\
$\begin{array}{l}\text { Tengku } \\
\text { Turulhuda } \\
\text { Rahim, } 2017\end{array}$ & $\begin{array}{l}\text { It achieves a score of } \\
\text { 90\% for the most } \\
\text { weighted exam } \\
\text { questions. }\end{array}$ & $\begin{array}{l}\text { Exam question } \\
\text { weightage } \\
\text { percentage has an } \\
\text { average value of } \\
70 \% \text {. }\end{array}$ \\
\hline $\begin{array}{l}\text { This } \\
\text { Research }\end{array}$ & $\begin{array}{l}\text { The greatest } \\
\text { percentage of } \\
\text { weighted exam } \\
\text { questions is 95\%. }\end{array}$ & $\begin{array}{l}\text { Exam question } \\
\text { weighted average is } \\
84 \text { percent, while the } \\
\text { lowest is 60 percent. }\end{array}$ \\
\hline
\end{tabular}

Table 5 compares two studies; the findings indicate that the suggested framework outperforms the first and secondstudies in terms of weighted percentage of test questions and marginally outperforms the weighted average of exam questions, owing to the adoption of the k-means technique and function. Random order, which aided in reducing question frequency by selecting a random population from the questionbank.

\section{CONCLUSION}

The generator will auto-prepare novel exam questions dependent on the Genetic Algorithm (GA), as well as assess different levels of learners based on Bloom's cognitive domains and educatorselected chapters.

Question banks consist of 800 questions. They were divided into 
six groups with identical characteristics using the $\mathrm{k}$ meansin the first step, and then each group was randomly arranged using a random sorting function to ensure that the questions were not replicated when the initial population was generated. After that, the genetic algorithm was used to obtain the best exam results.

\section{REFERENCES}

[1] Teo, Noor Hasimah Ibrahim, Nordin Abu Bakar, andSuraya Karim. "Designing GA-based auto- generatorof examination questions." 2012 Sixth UKSim/AMSS European Symposium on Computer Modeling and Simulation. IEEE, 2012.

[2] Abd Rahim, Tengku Nurulhuda Tengku, et al. "Automated exam question generator using genetic algorithm." 2017 IEEE Conference on e- Learning, e-Management and eServices (IC3e). IEEE, 2017.

[3] Shanthi, Bangera Shanika Ashok, Leona Josline Rego Harshitha, and K. Manasa. "Automated Exam Question Generator Using Genetic Algorithm."(2019).

[4] Paul, Dimple Valayil. "Automatic Question Paper Pattern Generation using GA Approach." INFOCOMP Journal of Computer Science 19.1 (2020).

[5] Immanuel and Tilasi.B, "Framework for Automatic Examination Paper Generation System," International Journal of Computer Science and Technology, vol. 6, no. 1, pp. 128-130, 2015.

[6] Chen, Yingrui, Mark Elliot, and Joe Sakshaug. "Genetic algorithms in matrix representation and its application in synthetic data." UNECE work session on statistical data confidentiality (2017).

[7] Song, Wanli. "Online Test Paper Composition Based on Genetic Algorithm." 2018 3rd International Conference on Modelling, Simulation and Applied Mathematics (MSAM 2018). Atlantis Press, 2018.

[8] Abd Rahim, Tengku Nurulhuda Tengku, et al. "Automated Exam Question Set Generator Using Utility Based Agent and Learning Agent." International Journal of Machine Learning and Computing 10.1 (2020).

[9] Paul, Dimple Valayil. "Automatic Question Paper Pattern Generation using GA Approach." INFOCOMP Journal of Computer Science 19.1 (2020).

[10] Amria, Ashraf, Ahmed Ewais, and Rami Hodrob. "A Framework for Automatic Exam Generation based on Intended Learning Outcomes." CSEDU (1). 2018.

[11] Shanthi, Bangera Shanika Ashok, Leona Josline Rego Harshitha, and K. Manasa. "Automated Exam

[12] Question Generator Using Genetic Algorithm." (2019).
[13] Abd Rahim, Tengku Nurulhuda Tengku, et al. "Automated exam question generator using genetic algorithm." 2017 IEEE Conference on e-Learning, e- Management and eServices (IC3e). IEEE, 2017.

[14] Chavan, Aishwarya, et al. "Automated question paper generator system using apriori algorithm and fuzzy logic." International Journal for Innovative Research in Science \& Technology 2.11 (2016): 707- 710.

[15] A. Immanuel and Tilasi.B, "Framework for Automatic Examination Paper Generation System," International Journal of Computer Science and Technology, vol. 6, no. 1, pp. 128-130, 2015.

[16] Graña, Manuel, et al., eds. International Joint Conference SOCO'16-CISIS'16-ICEUTE'16:San Sebastián, Spain, October 19th-21st, 2016 Proceedings. Vol. 527. Springer, 2016.

[17] Jain, A. K. (2010). Data clustering: 50 years beyond Kmeans. Pattern Recognition Letters 31(8): 651- 666.

[18] Marutho, Dhendra, Sunarna Hendra Handaka, and Ekaprana Wijaya. "The determination of cluster number at k-mean using elbow method and purity evaluation on headline news." 2018 International Seminar on Application for Technology of Information and Communication. IEEE, 2018.

[19] Poikolainen, I., F. Neri, and F. Caraffini, Clusterbased population initialization for differential evolution framworks. Information Sciences, 2015. 297: p. 216-235.

[20] D. Hermawanto, "Cornell University Library," 8 2013.[Online].

Available: http://arxiv.org/ftp/arxiv/papers/1308/1308.467 5.pdf. [Accessed 2210 2015].

[21] L. Jacobson, "Creating," 122 2012. [Online]. Available: http://www.theprojectspot.com/tutorial- post/creating-ageneticalgorithm-for- beginners/3. [Accessed 1812 2015].

[22] Kapil, Shruti, Meenu Chawla, and Mohd Dilshad Ansari. "On K-means data clustering algorithm with genetic algorithm." 2016 Fourth International Conference on Parallel, Distributed and Grid Computing (PDGC). IEEE, 2016.

[23] N. H. I. Teo, N. A. Bakar and M. R. A. Rashid, "Representing Examination Question Knowledge into Genetic Algorithm," in IEEE Global Engineering Education Conference (EDUCON), Istanbul, 2014.

[24] D. Hermawanto, "Cornell University Library," 8 2013.[Online]. http://arxiv.org/ftp/arxiv/papers/1308/1308.467 [Accessed 2210 2015]. 